\title{
Plasminogen Activator Interaction
}

National Cancer Institute

\section{Source}

National Cancer Institute. Plasminogen Activator Interaction. NCI Thesaurus. Code C40529.

Plasminogen Activator Interaction involves temporary non-covalent binding through intermolecular physical forces of attraction with heterogeneous group of widely expressed lysosomal and secreted serine proteases having fibrin-binding activity that convert plasminogen to fibrinolytic plasmin. Inhibited by PAI-1, encoded by the PLAT Gene (Peptidase S1 Family), and cleaved by plasmin, tissue kallikrein, or factor XA to disulfide-linked A/B chains, tissue-type plasminogen activator plays a role in cell migration and tissue remodeling. 